Pesquisa e Reflexão em Educação Básica

\title{
O direito à educação de jovens e adolescentes em privação de liberdade
}

Thaís Farias de Almeida ${ }^{1}$

Larissa Davis Moraes²

\begin{abstract}
Resumo:
A legislação brasileira defende a educação como um direito social, público e subjetivo, sendo essencial na promoção da cidadania e da dignidade da pessoa humana. No entanto, as políticas públicas, em especial as educacionais, não têm se mostrado eficazes para os jovens e os adolescentes que, subordinados às medidas privativas de liberdade, de longe experienciam uma efetiva oportunidade de (re)socialização. Neste sentido, o presente artigo objetiva discutir acerca do direito à educação no contexto dos jovens e adolescentes em privação de liberdade, os quais apresentam peculiaridades e vulnerabilidades sociais no ambiente da unidade de internação. Para tanto, foram realizadas pesquisas bibliográficas, endossadas por coletas físicas e virtuais, se utilizando o método de abordagem dedutivo. À título de considerações finais, foi pontuado que a educação dentro das unidades de internação é de suma importância para o processo de inclusão social e para a consumação do direito fundamental à proteção integral dos jovens e adolescentes em conflito com a lei, ao passo que oferta condições para que eles consigam acreditar na existência de um futuro melhor e digno.
\end{abstract}

\section{Palavras-chave:}

Direito à educação. Medida socioeducativa de internação. Jovens e adolescentes em conflito com a lei.

\section{The education right for young people and teenagers in privation of liberty}

Abstract: The Brazilian legislation defends the education as a social, public and subjective right, being essential to promote citizenship and human dignity. However, public policies, especially the educational ones, have not proven to be effective for young people and teenagers who, subordinated to privative measures of liberty, from far away experience an effective opportunity for (re)socialization. In this sense, the present article aims to discuss about the education right in the context of young people and teenagers in privation of liberty, who presents social peculiarities and vulnerabilities in the environment of the custodial units. For this, bibliographic searches were carried out, supported by physical and virtual

1 Graduada em Direito pelo Centro Universitário UNIFACISA. Pós-graduanda em Direito Penal e Processo Penal. E-mail: thaisfalmeida3@gmail.com. ORCID iD: http://orcid.org/0000-0001-7252-3941.

2 Mestranda em Educação na Universidade Estadual Paulista “Júlio de Mesquita Filho" (UNESP), Campus de Rio Claro. E-mail: larissa_2108@hotmail.com. ORCID iD: http://orcid.org/0000-0002-2401-3573. 
data collect, using the deductive approach method. As final considerations, it was pointed that education in the custodial units is of utmost importance for the process of social inclusion and for the consummation of the fundamental right to the whole protection of young people and teenagers in conflict with the law, while that it offers conditions for them to believe in the existence of a better and dignified future.

Keywords: Education right. Socio-educational measure of internment. Young people and teenagers in conflict with the law.

\section{El derecho a la educación de los jóvenes y adolescentes en privación de libertad}

Resumén: La legislación brasileña defiende la educación como un derecho social, público y subjetivo, siendo esencial en la promoción de la ciudadanía y la dignidad humana. Sin embargo, las políticas públicas, especialmente las educativas, no han mostrado ser eficaces para los jóvenes y adolescentes que, subordinados a las medidas de privación de libertad, de lejos experimentan una oportunidad efectiva de (re)socialización. En este sentido, en el presente artículo se pretende discutir sobre el derecho a la educación en el contexto de los jóvenes y adolescentes en privación de libertad, que presentan peculiaridades y vulnerabilidades sociales en el ámbito de la unidad de detención. Para eso, fueron realizadas investigaciones bibliograficas, avaladas por colectas físicas y virtuales, usando el método de enfoque deductivo. Como consideraciones finales, se señaló que la educación en las unidades de detención es de suma importancia para el proceso de inclusión social y para la consumación del derecho fundamental a la plena protección de los jóvenes y adolescentes en conflicto con la ley, al tiempo que les ofrece condiciones para que puedan creer en la existencia de un futuro mejor y digno.

Palabras clabe: Derecho a la educación. Medida de internamiento socio-educativo. Jóvenes y adolescentes en conflicto con la ley.

\section{Introdução}

O direito à educação foi reconhecido como um direito social na Constituição Federal de 1988, a qual estabeleceu o dever do Estado e da família em promovê-lo e incentivá-lo, com a colaboração da sociedade, reconhecendo o acesso ao ensino obrigatório e gratuito como um direito público e subjetivo. Pode-se afirmar, ainda, que a educação possui status de direito humano e fundamental, por ser consagrada em instrumentos normativos internacionais.

Tendo em vista o caráter essencial da educação na promoção da cidadania e da dignidade da pessoa humana, o presente artigo visa discutir sobre o referido direito no contexto dos jovens e adolescentes em cumprimento de medida privativa de liberdade, isto é, a medida de internação em estabelecimento socioeducativo, diante das suas peculiaridades e vulnerabilidades sociais.

O estudo em tela mostra-se relevante, pois o direito à educação dos jovens e adolescentes em situação de conflito com a lei merece uma especial atenção por parte do Estado, para que seja realmente efetivado, objetivando promover uma (re)socialização eficaz dos que se encontram no ambiente de uma unidade de internação.

Sendo assim, inicialmente, refletiremos a respeito dos direitos fundamentais dos jovens e adolescentes e suas distinções conceituais, para, em seguida, explicitarmos acerca da medida socioeducativa de internação, prevista no Estatuto da Criança e do Adolescente (ECA). Logo após, abordaremos sobre o direito à educação, e, por fim, discutiremos sua aplicabilidade no âmbito dos jovens e adolescentes em privação de liberdade.

À título de considerações finais, concluímos que a educação pode contribuir para a efetivação do direito fundamental à proteção integral dos jovens e adolescentes em conflito com a lei, uma 
vez que ela consiste em um mecanismo de inclusão social, de modo que amplia os horizontes do indivíduo e auxilia com condições para que ele consiga acreditar em um futuro melhor e digno, rompendo o ciclo da reiteração infracional.

\section{Metodologia}

A presente pesquisa se classifica como qualitativa e explicativa, tendo como método de abordagem o método dedutivo. Além disso, foi realizada a partir da técnica de pesquisa da documentação indireta, mediante um estudo de legislações, doutrinas, dissertações, monografias e artigos científicos, ou seja, de pesquisas bibliográficas, por meio de coleta físico e virtual.

\section{Os direitos fundamentais dos jovens e adolescentes}

O âmbito do Direito Penal, há tempos, se preocupou em dar tratamento especial para as crianças e os adolescentes, uma vez que a fragilidade ou o próprio desenvolvimento, em razão da idade do indivíduo, influencia na sua capacidade e velocidade de aprendizado. A partir dessa visão, já nos séculos passados, se buscou promover uma maior atenção e distinção aos infantes na seara do cometimento de condutas ilícitas (VOLPI, 2002, p. 14).

Ao observarmos a legislação brasileira, notaremos nos textos das leis que, ao longo da história, crianças e adolescentes eram responsabilizados e punibilizados por seus atos de forma diferenciada dos adultos. Conforme Prates (2001, p. 53), o Decreto no 17.943-A, ainda do ano de 1927, já revelava uma preocupação legal com os menores de 18 (dezoito) anos. No decreto, foi trazida a garantia ao "menor infrator" de tratamento apropriado a suas condições de saúde, o direito a reinserção em ambiente familiar, bem como se previu sua proteção e assistência.

Embora de grande valia à lembrança dos direitos das crianças e dos adolescentes, apenas com a Constituição Federal de 1988, no artigo 228, que emergiu a garantia da inimputabilidade do menor de 18 (dezoito) anos e trouxe a positivação da necessidade de uma regulamentação especial para os adolescentes - considerados assim a partir de 12 (doze) anos de idade - que se envolvessem em práticas ilícitas (BRASIL, 1988).

Com efeito, a fim de atender a ordem do artigo 228 da Constituição Federal, está em vigência a Lei no 8.069/90, o Estatuto da Criança e do Adolescente (ECA), que, de acordo com Elias (2005, p. 3), também elucida a distinção entre criança e adolescente: "o art. 2o do ECA preceitua que, até doze anos de idade incompletos, o indivíduo é criança e, a partir daí até dezoito, adolescente".

O referido diploma legal instaurou ações capazes de proteger e enrijecer os direitos fundamentais das crianças e dos adolescentes, os quais se amparam na Constituição Federal de 1988, enraizando os princípios e as diretrizes da doutrina da proteção integral, de maneira a exceder a antiga e ultrapassada cultura "menorista" (CUSTÓDIO, 2009, p. 43).

No seu artigo 3o, o ECA se refere à proteção integral destinada à criança e ao adolescente, afirmando que estes:

[...] gozam de todos os direitos fundamentais inerentes à pessoa humana, sem prejuízo da proteção integral de que trata esta Lei, assegurando-lhes, por lei ou por outros meios, todas as oportunidades e facilidades, a fim de lhes facultar o desenvolvimento físico, mental, moral, espiritual e social, em condições de liberdade e de dignidade. (BRASIL, 1990).

Por conseguinte, no artigo 15, as crianças e os adolescentes são reconhecidos como detentores do direito à liberdade, ao respeito e à dignidade como pessoas humanas em processo de 
desenvolvimento e como sujeitos de direitos civis, humanos e sociais previstos em leis e na Constituição Federal (BRASIL, 1990).

Apesar da importante evolução de direitos ocasionada pelo ECA, este teve como foco o grupo das crianças e dos adolescentes. Dessa forma, os jovens com mais de 18 (dezoito) anos de idade ficaram fora de movimentos e programas sociais, não obstante se observe que muitos deles também apresentam desafios a serem enfrentados, "por estarem ainda construindo seus espaços e modos de inserção" (ABRAMO; LEÓN, 2005, p. 8).

Existe hoje, no Brasil, um uso concomitante dos dois termos, adolescência e juventude, que ora se entrelaçam, ora constituem campos distintos, todavia se complementam. De todas as definições que são desenvolvidas, a ideia de juventude remete a fase do ciclo vital entre a infância e a maturidade. Contudo, há uma tendência nacional que se baseia nos critérios das Nações Unidas e de instituições oficiais, pelos quais foi estabelecida uma faixa etária para o período da juventude: entre os 15 (quinze) e os 24 (vinte e quatro) anos, levando em consideração as variações existentes conforme as situações sociais e trajetórias pessoais de cada caso concreto (ABRAMO; LEÓN, 2005, p. 6-7).

Em razão de serem utilizadas diferentes terminologias para se referir ao público que será analisado neste artigo, cumpre esclarecer a distinção entre jovem e adolescente, ressaltando-se que ambas as expressões serão utilizadas no decorrer do trabalho. Assim, segundo Abramo e León (2005, p. 8),

[...] a adolescência corresponde à primeira fase (tomando como referência a faixa etária que vai dos 12 aos 17 anos, como estabelecido pelo ECA), caracterizada principalmente pelas mudanças que marcam esta fase como um período específico de desenvolvimento, de preparação para uma inserção futura; e juventude (ao que alguns agregam o qualificativo propriamente dito, ou então denominam como jovens adultos, ou ainda pós adolescência) para se referir à fase posterior, de construção de trajetórias de entrada na vida social.

Nesse contexto, conforme preconiza a Constituição Federal, pode-se afirmar que as crianças, os adolescentes e os jovens são detentores de direitos fundamentais, como o direito à vida, à saúde, à alimentação, à educação, ao lazer, à profissionalização, à cultura, à dignidade, ao respeito, à liberdade e à convivência familiar e comunitária, tendo a família, a sociedade e o Estado o dever de "colocá-los a salvo de toda forma de negligência, discriminação, exploração, violência, crueldade e opressão" (BRASIL, 1988).

Entretanto, a positivação das mencionadas garantias fundamentais ainda não anula a inexistência de direitos e princípios mitigados, negligenciados ou até mesmo violados. Quando olhamos para a aplicação das medidas socioeducativas aos adolescentes em conflito com a lei, veremos que essa realidade de supressão de direitos é real e preocupante, sobretudo diante do modelo atual de justiça punitivista.

De acordo com o ECA, aos adolescentes que infringirem a lei serão impostas medidas socioeducativas, que serão destinadas à formação do tratamento integral empreendido, com o objetivo de reestruturar e ressocializar o adolescente ou o jovem para este alcançar a normalidade da integração social (ALVES, 2006, p. 46).

À vista disso, a doutrina da proteção integral é o fundamento para assegurar os direitos dos jovens e dos adolescentes e atingir a finalidade da medida socioeducativa. Para tanto, se faz importante que se estabeleça uma proposta socioeducativa, contando com orientação pedagógica, psicológica e profissional (MATOS, 2011, p. 37).

Seguindo essa perspectiva, as medidas socioeducativas previstas no ECA possuem caráter educativo e pedagógico, devendo priorizar a maturidade pessoal, a afetividade e a própria humanidade daqueles que se encontram na condição peculiar de desenvolvimento de suas personalidades (ELIZEU, 2010, p. 33). 
Depreende-se, portanto, que tais medidas devem ser trabalhadas para o desenvolvimento dos jovens e dos adolescentes, visando uma orientação quanto aos seus direitos e deveres perante a sociedade. Não obstante, deve-se buscar a formação profissional, para que, finalizado o cumprimento da medida, tenham condições de empregabilidade e, dessa forma, sejam reinseridos na sociedade, certos de que a ela pertencem (MATOS, 2011, p. 37).

No entanto, o Direito Penal Juvenil, ao se deparar com o adolescente ou o jovem em situação de conflito com a lei, diferentemente do que propõe o ECA, o trata sob a perspectiva de sua culpabilidade e impõe, na maioria dos casos, uma medida socioeducativa pautada no padrão punitivo, que definiu a pena privativa de liberdade como o principal instrumento de resposta ao delito, mitigando direitos e princípios.

Nesse aspecto, questiona-se se na imposição da medida socioeducativa (MSE), em específico a de internação, a qual priva o direito à liberdade do adolescente ou jovem e o restringe do direito à convivência familiar, comunitária e inclusão social integral, o princípio da proteção integral está sendo observado. Assim,

[...] em vez de promover uma prática pedagógica voltada para auxiliar o desenvolvimento dos jovens, a MSE de internação tem pautado suas ações na manutenção de práticas punitivas e da não garantia de direitos, sendo reforçada ainda por ações que contribuem com essa lógica por meio da minimização do sofrimento, em vez de combatê-las. Esses aspectos levam a compreensão sobre a ausência da função socioeducativa na aplicação da MSE, evidenciada pela falta de uma intencionalidade pedagógica capaz de promover projetos de vida para os jovens que sejam diferentes das condições que os levaram ao cumprimento da MSE. (COSTA; ALBERTO; SILVA, 2019).

Mas não só isso, questiona-se ainda a MSE de internação quanto a sua legítima eficácia ou ineficácia a respeito do sistema atual punitivo, na perspectiva da ressocialização do adolescente ou jovem em conflito com a lei e, ainda, se atende a real finalidade de sua recuperação, despertando nele consciente responsabilização pela prática do ato infracional.

Isto posto, tendo em vista os direitos dos jovens e dos adolescentes na legislação brasileira, no seguinte tópico se discorrerá acerca da mencionada MSE de internação, possibilitando uma maior compreensão e aprofundamento sobre seu conteúdo, para, ao fim, discutirmos em relação ao direito educacional dos que estão em seu cumprimento.

\section{A medida socioeducativa de internação}

Como dito anteriormente, segundo o artigo 228 da Constituição Federal, a inimputabilidade penal foi fixada em 18 (dezoito) anos de idade, sendo o mencionado dispositivo legal considerado cláusula pétrea, uma vez que consiste em um direito individual de natureza análoga aos direitos elencados no artigo 5o da referida lei, o qual apresenta uma gama de garantias fundamentais à vida humana digna (BRASIL, 1988).

Do ponto de vista infraconstitucional, o Estatuto da Criança e do Adolescente (ECA) considerou ser adolescente a pessoa com 12 (doze) a 18 (dezoito) anos de idade, estabelecendo a responsabilização deste por ato infracional, caso venha a praticar conduta prevista como crime ou contravenção penal na legislação brasileira (BRASIL, 1990).

Importante frisar que a terminologia do "ato infracional" procura evidenciar o caráter extrapenal da matéria, objetivando atentar acerca do atendimento que deve ser prestado ao adolescente em conflito com a lei, sujeito de direitos e merecedor de proteção integral (DIGIÁCOMO, M. J.; DIGIÁCOMO, I. A., 2020, p. 218). 
Com efeito, as crianças e os adolescentes não preenchem o requisito da culpabilidade, pressuposto de aplicação da pena de uma infração penal, empregando-se aos mesmos a presunção absoluta da incapacidade de entender e determinar-se. Destarte, no Brasil, adotou-se o critério biológico para se aferir a imputabilidade, isto é, a capacidade de compreender a vedação de certo comportamento pelo ordenamento jurídico e de determinar-se de acordo com este entendimento (ISHIDA, 2015, p. 254).

Dessa forma, o adolescente só será privado de sua liberdade em situação flagrante de ato infracional ou por ordem escrita e fundamentada da autoridade judiciária competente, sendo o processo e o julgamento do procedimento realizados na Vara da Infância e da Juventude do local da conduta (DIGIÁCOMO, M. J.; DIGIÁCOMO, I. A., 2020, p. 350).

Após os trâmites do procedimento especial de natureza educativa e ouvido o Ministério Público, o magistrado poderá aplicar ao adolescente quaisquer das medidas socioeducativas mais adequadas a situação, todas previstas no ECA, quais sejam: advertência; obrigação de reparar o dano; prestação de serviços à comunidade; liberdade assistida; inserção em regime de semiliberdade e internação em estabelecimento educacional (BRASIL, 1990).

A internação é considerada a medida mais rigorosa entre as demais, a qual deve ser reavaliada pelo juiz a cada 6 (seis) meses. Quando a internação ocorrer antes da sentença, para garantir a segurança do adolescente ou da ordem pública, é denominada de internação provisória, a qual não poderá ultrapassar o período de 45 (quarenta e cinco) dias. Sendo em razão de sentença da autoridade judiciária, trata-se de internação definitiva, tendo esta duração máxima de 3 (três anos) ou até que o adolescente complete 21 (vinte e um) anos de idade (BRASIL, 1990).

Ressalta-se que, consoante a Súmula 605 do Superior Tribunal de Justiça (STJ), a superveniência da maioridade penal não interfere na apuração de ato infracional nem na aplicabilidade de medida socioeducativa em curso, enquanto não atingida a idade de 21 (vinte e um) anos. Assim, não obstante $o$ ato ter sido praticado ainda na adolescência, o jovem de até 21 (vinte e um) anos de idade irá continuar o cumprimento da internação que já lhe foi imposta (BRASIL, 2018).

Visando os direitos e o desenvolvimento do jovem e do adolescente, o ECA condicionou três princípios para a aplicação da medida de internação, sendo eles: o da brevidade, em respeito a necessidade de readaptação do adolescente; o da excepcionalidade, pelo qual a referida medida deve ser a última a ser aplicada pelo juiz, ou seja, quando houver a ineficácia de outras, e, por fim, o do respeito à condição peculiar de pessoa em desenvolvimento (ISHIDA, 2015, p. 307).

Ademais, preconiza o artigo 122 do referido diploma legal que a medida de internação só poderá ser aplicada quando se tratar de ato infracional cometido com violência ou grave ameaça à pessoa, por reiteração no cometimento de infrações graves e diante do descumprimento reiterado e injustificável da medida anteriormente imposta (DIGIÁCOMO, M. J.; DIGIÁCOMO, I. A., 2020, p. 269-270).

É oportuno destacar que não existe prévia correlação entre o ato infracional praticado e a sanção socioeducativa, sendo a aferição da solução mais adequada condicionada a inúmeros fatores, que demandam um estudo criterioso, o qual vai além da singela comprovação da autoria e da materialidade do ato infracional, passando por uma avaliação técnica das circunstâncias em que esse foi praticado, da capacidade do adolescente em se submeter à medida, suas necessidades pedagógicas específicas, dentre outros aspectos (DIGIÁCOMO, M. J.; DIGIÁCOMO, I. A., 2020, p. 269-270).

Nesse sentido, o juiz poderá escolher a medida socioeducativa mediante três critérios, visando a proteção integral do adolescente, quais sejam: a gravidade do delito; a primariedade do adolescente, isto é, se ele praticou o ato infracional pela primeira vez ou não, e sua vinculação com a família natural ou extensa, ocasião em que será avaliado se há uma chance de ele se recuperar junto ao seio familiar, aplicando-lhe uma medida mais branda ou com o acompanhamento de um setor técnico e da própria família (ISHIDA, 2015, p. 293).

Conforme a Lei no 12.594/12, as medidas socioeducativas podem ser executadas em meio aberto, como ocorre com a liberdade assistida e a prestação de serviços à comunidade, ou em meio 
fechado, que seriam a semiliberdade e a internação. A referida lei estabelece que os municípios serão responsáveis pelas medidas em meio aberto, enquanto os estados pelas medidas em meio fechado, tendo a União que "fixar diretrizes sobre a organização, funcionamento e programas de atendimento das unidades e as normas de referência destinadas ao cumprimento dessas medidas" (CARREIRA; ANDRADE, 2016, p. 418).

O centro socioeducativo destinado ao cumprimento de medida de internação consiste em um ambiente fechado, em que os direitos humanos e fundamentais dos jovens e adolescentes em situação de conflito com a lei se fazem, muitas vezes, restringidos. Sendo assim, é importante discutir sobre o direito à educação nessa perspectiva da privação de liberdade. Inicialmente, no seguinte tópico, será explicitado acerca do referido direito, para, logo em seguida, o especificarmos no contexto dos que estão em cumprimento da medida de internação.

\section{O direito à educação}

A Declaração Universal de Direitos Humanos de 1948, surgida no período pós Segunda Guerra Mundial, afirma que a educação é um direito de todas as pessoas, devendo ser gratuita e obrigatória ao menos quanto ao ensino fundamental. No aspecto do referido documento, o direito humano à educação se caracteriza como um "direito de empoderamento", que almeja o pleno desenvolvimento da personalidade humana, o sentido de sua dignidade e o fortalecimento dos direitos humanos (MORAIS, 2019, p. 21-23).

Criado a fim de dar exigibilidade jurídica aos dispositivos constantes na Declaração Universal de Direitos Humanos de 1948, o Pacto Internacional de Direitos Econômicos, Sociais e Culturais foi ratificado pelo Brasil em 1992, tendo o país se comprometido em cumprir as garantias humanas e fundamentais ali estabelecidas, uma vez que sua eventual inobservância pode ensejar a responsabilização do Estado no contexto do Direito Internacional Público (MORAIS, 2019, p. 22-23).

No âmbito interno, a Constituição Federal de 1988 trata especificamente da educação nos artigos 205 a 214, situados na Seção I do Capítulo III, intitulado Da educação, da cultura e do desporto, ocasião em que a define como sendo um direito de todos, trazendo para o Estado e para a família o dever de promovê-la e de incentivá-la, juntamente "com a colaboração da sociedade, visando ao pleno desenvolvimento da pessoa, seu preparo para o exercício da cidadania e sua qualificação para o trabalho" (BRASIL, 1988).

O mencionado diploma legal prevê um rol de princípios norteadores para a organização do ensino, pondo em destaque sua gratuidade, a permanência na escola, a liberdade de aprender, ensinar, pesquisar e divulgar o pensamento, a arte e o saber, o respeito ao pluralismo de ideias e de concepções pedagógicas, a valorização dos profissionais da educação (com a previsão de um piso salarial nacional), a gestão democrática do ensino público e, principalmente, a exigência de um padrão de qualidade (BRASIL, 1988).

O texto constitucional estabelece o acesso ao ensino como obrigatório e gratuito, considerando-o um direito público subjetivo e tornando a educação básica obrigatória e gratuita às crianças e aos adolescentes dos 04 (quatro) aos 17 (dezessete) anos de idade, bem como àqueles que a ela não tiveram acesso na idade própria, devendo o Estado oferecer "atendimento ao educando, em todas as etapas da educação básica" (BRASIL, 1988).

Vale ressaltar que o reconhecimento expresso do direito à educação como um direito subjetivo público apresenta extrema importância, tendo em vista que possibilita ao cidadão exigir do poder público a concretização desse direito fundamental, pois os administradores públicos terão uma obrigação legal para com a população no sentido de efetivar seu cumprimento (MEDEIROS; RODRIGUES, 2014, p. 12).

Inclusive, a Constituição Federal garante a responsabilidade da autoridade competente caso o Estado não ofereça o ensino obrigatório ou realize sua oferta de maneira irregular. Desse modo, 
estabelece que compete ao poder público "recensear os educandos no ensino fundamental, fazer-lhes a chamada e zelar, junto aos pais ou responsáveis, pela frequência à escola” (BRASIL, 1988).

Cabe destacar que a disposição legal da frequência obrigatória à escola é determinada para toda a população infanto-juvenil, porém tal ferramenta "assume contornos ainda mais contundentes, quando direcionada a adolescentes infratores", uma vez que o menor se torna mais vulnerável à criminalidade quando está fora do contexto escolar, o qual seria o responsável por envolvê-lo em "atividades que seriam fatores de proteção para o afastamento da delinquência" (CUNHA; DAZZANI, 2018, p. 35).

Na legislação brasileira infraconstitucional, o direito à educação se encontra previsto no rol dos direitos elencados no artigo 4o do Estatuto da Criança e do Adolescente (ECA), que devem ser efetivados, com absoluta prioridade, pela família, pela comunidade, pela sociedade em geral e pelo poder público, especialmente no contexto de privação de liberdade do adolescente (BRASIL, 1990).

Nesse diapasão, o ECA visa assegurar o direito a uma educação que valorize o desenvolvimento integral do adolescente, como um instrumento indispensável para promover a doutrina da proteção integral, a partir de "uma formação voltada a prática da cidadania e capacitação para o trabalho, sempre preconizando o respeito absoluto aos direitos fundamentais" (SILVA, 2019, p. 67).

Por fim, dentro da perspectiva da Constituição Federal de 1988, o artigo 5o da "Lei de Diretrizes e Bases da Educação Nacional” (Lei no 9.934/96) estabeleceu que o acesso à educação básica é um direito público subjetivo, devendo ser oferecida em qualquer situação na qual se encontre o educando, de acordo com suas necessidades (BRASIL, 1996).

Diante da presente exposição sobre o direito à educação no ordenamento jurídico brasileiro, no próximo tópico discutiremos acerca de sua aplicabilidade no âmbito dos adolescentes e jovens em cumprimento de medida socioeducativa de internação, ao passo que serão tecidas análises quanto a sua importância no ambiente de privação de liberdade.

\section{O direito à educação dos jovens e adolescentes privados de liberdade}

Em relação ao direito à educação dos jovens e adolescentes em conflito com a lei, o Estatuto da Criança e do Adolescente (ECA) expressa, em seus artigos 123 e 124, que durante o período de cumprimento da medida de internação serão obrigatórias as atividades pedagógicas, bem como que a pessoa privada de liberdade possui o direito de receber escolarização e profissionalização, além de realizar atividades culturais, esportivas e de lazer (BRASIL, 1990).

Observando os preceitos constitucionais e os princípios adotados pelo ECA, a Lei no 12.594/12 instituiu o Sistema Nacional de Atendimento Socioeducativo (SINASE), objetivando regulamentar a execução das medidas socioeducativas (MSE), de modo a garantir a inserção de jovens em cumprimento de MSE na rede pública de educação, em qualquer fase do período letivo, contemplando as diversas faixas etárias e níveis de instrução (BRASIL, 2012).

Para mais, o SINASE apresenta o escopo de assegurar ao adolescente ou jovem privado de liberdade o acesso aos direitos e oportunidades de superação de sua situação de exclusão, como também à formação de valores para a participação na vida social, por meio da oferta da escolarização básica e de práticas pedagógicas e educativas (OLIVEIRA, 2014, p. 59).

Assim, pode-se inferir que o SINASE preconiza o caráter educativo e pedagógico das medidas socioeducativas previstas no ECA, não obstante se perceba uma natureza sancionatória na MSE de internação, posto que ocasiona a restrição da liberdade do adolescente ou jovem em estabelecimento educacional fechado (ROQUETE, 2014, p. 7).

Conforme a Resolução no 3 do Ministério da Educação, datada de 13 de maio de 2016, as unidades de internação devem apresentar espaço de escolarização próprio, com infraestrutura adequada, recursos pedagógicos necessários e equipe pedagógica e administrativa qualificada, 
garantindo-se a qualidade do ensino ofertado, sendo responsabilidade do poder público investir em práticas pedagógicas inovadoras a serem destinadas aos socioeducandos (SILVA, 2019, p. 73).

Sendo assim, a execução da MSE de internação deve observar os princípios direcionados aos adolescentes e jovens em geral, com o propósito de garantir que o período da restrição de liberdade não viole seus direitos fundamentais e sociais. Portanto, havendo sua aplicação, o Estado deve oferecer oportunidades verdadeiras e acessíveis de educação, profissionalização e apoio psicossocial (CNJ, 2012, p. 7).

Todavia, esse atendimento a ser ofertado demanda qualificação no quesito da educação escolar, devido à especial circunstância em que se encontram os socioeducandos, além do fato de a maioria dos adolescentes entrarem nos centros de internação apresentando um histórico acentuado de evasões escolares e idade defasada na vida escolar (OLIVEIRA, 2014, p. 87).

Observa-se que, no âmbito da medida restritiva de liberdade, o adolescente ou o jovem recebe instrução escolar e profissional dentro da própria unidade de internação, na qual devem funcionar escolas comuns (CUNHA, 2015, p. 3). Neste sentido, a oferta de educação surge na tentativa de promover-lhe meios e caminhos lícitos de autossustento, visando o seu distanciamento da criminalidade e dos "circuitos laborais delituosos" (CUNHA; DAZZANI, 2018, p. 35). Dessa forma,

O afastamento da escola, por expulsão ou por processos sutis de exclusão (baixo desempenho, relação conflituosa entre professores e alunos, clima escolar ruim etc.), configura-se em um marco importante para a entrada ou para o agravamento da conduta delituosa, porque parece tornar os adolescentes mais vulneráveis, pelo tempo ocioso, sem supervisão, e ligação com pares divergentes, nesse período sem atividades [...] Tem-se, portanto, que a frequência escolar, per si, pode constituir-se em um fator de proteção do adolescente quando esta fortalece sua rede prossocial e garante uma rotina minimamente convencional. (BAZON; SILVA; FERRARI, 2013, p. 193).

No cenário das medidas socioeducativas, o direito à educação se mostra como um dos precursores no processo de ressignificação para os jovens e adolescentes em conflito com a lei, principalmente analisando-se na perspectiva daqueles que se encontram em privação de liberdade (ANTÃO, 2012, p. 31). Já entendia Michel Foucault que:

A educação do detento é, por parte do poder público, ao mesmo tempo uma precaução indispensável no interesse da sociedade e uma obrigação para com o detento. Só a educação pode servir de instrumento penitenciário. A questão do encarceramento penitenciário é uma questão de educação. (FOUCAULT, 2014, p. 265).

Segundo Roquete (2014, p. 9-10), a relação entre a ausência da educação e o envolvimento dos adolescentes com atos infracionais pode ser observada através dos dados apresentados pelo Conselho Nacional de Justiça (CNJ) no ano de 2012, os quais mostraram que a baixa escolaridade consiste em uma das características presentes no perfil do socioeducando em condição de internação:

[...] a maioria dos adolescentes internados (entre 16 e 17 anos) não concluiu o Ensino Fundamental, a maioria possui apenas o 6o ano do Ensino Fundamental, 8\% dos adolescentes internados são analfabetos, sendo que $44 \%$ destes estão na região Nordeste [...] o desafio, além de garantir o direito à educação para adolescentes privados de liberdade, é oferecer uma educação na perspectiva emancipatória, capaz de torná-los conscientes leitores da realidade e participantes da sociedade. Ainda não existe uma política pública integrada entre o SINASE e a rede pública de educação dos estados para a educação do sistema socioeducativo de internação. (ROQUETE, 2014, p. 9-10). 
No Brasil, todavia, as políticas públicas norteadas para os jovens e adolescentes que cumprem medida socioeducativa de internação "tem sua expressão fragilizada à medida que os direitos desse segmento não são garantidos”. Por conseguinte, é necessário superar a perspectiva de cárcere, dando suporte a uma proposta educacional, promovendo uma universalização da escolarização (OLIVEIRA, 2014, p. 61).

Com isso, se faz importante a existência de um sistema educacional e pedagógico que acolha os jovens e adolescentes em conflito com a lei e almeje promover a aprendizagem, adaptando a atividade educativa às suas necessidades e possibilidades. No ambiente restritivo de liberdade, a atuação de um professor pode estimular o educando com seu interesse, levando em consideração suas especificidades, as características de sua faixa etária e suas experiências culturais.

De acordo com Francisco e Murgo (2015, p. 103-115),

Os professores serão os mediadores do conhecimento científico a ser difundido no processo de ensino e aprendizagem. E muito mais do que isso, poderão motivar esses adolescentes a terem um apreço positivo pelos estudos. Em contrapartida, Padovani e Ristum (2013) salientam que não é qualquer tipo de intervenção que deverá ser realizada na práxis pedagógica desses docentes [...] Padovani e Ristum (2013) defendem a necessidade de uma pedagogia específica para se trabalhar com o adolescente autor de atos infracionais, uma metodologia específica para atendê-lo, além de uma maneira distinta de lidar com ele. 'Faz-se necessário compreender e intervir nas múltiplas relações que o envolvem, resgatando, sobretudo, a sua capacidade criativa para o desenvolvimento de uma nova relação consigo mesmo e com o social'.

Nos espaços de privação de liberdade, são necessárias propostas educativas que envolvam todos que se encontram inseridos naquele contexto. Assim, o educador tem o desafio de efetivar práticas educativas que possam vencer o ambiente hostil, dando lugar a projetos pedagógicos que envolvam a conjuntura cultural e familiar do jovem, de maneira a "respeitar suas origens, suas limitações e seus desafios e propiciar que ele possa se expressar e se fazer ouvir" (JUNG, 2018, p. 7).

Vale destacar as palavras de Freire (2001, p. 26): "uma mesma compreensão da prática educativa, uma mesma metodologia de trabalho, não operam necessariamente de forma idêntica em contextos diferentes".

Seguindo esse entendimento, afirma Padovani e Ristum (2013, p. 982) que:

[...] faz-se necessária uma reflexão acerca da precariedade da instituição escolar dentro dos sistemas socioeducativos, a qual não apresenta um projeto político-pedagógico que considere as especificidades e o momento que o jovem em privação de liberdade está vivenciando [...] A descontinuidade no envolvimento com atos infracionais ocorre aos poucos, a partir de novas experiências e do surgimento de oportunidades de explorar novos caminhos. Essa descontinuidade relaciona-se a inúmeras vivências resultantes da interação do jovem com o ambiente que o cerca. Nesse sentido, a escola pode vir a ter uma efetiva atuação. Ao desconstruir/construir, distancia-se da linearidade e se aproxima de uma trajetória que envolve avanços e retrocessos.

Apesar de o Brasil possuir um bom aparato legislativo em relação aos direitos dos jovens e dos adolescentes, vê-se casos em que o próprio poder público deixa de efetivar o direito à educação para aqueles que se encontram em cumprimento de medida socioeducativa de internação, não obstante seja seu principal garantidor.

Foi o que ocorreu no ano de 2019 no estado do Rio de Janeiro, mais especificamente nas unidades do Departamento Geral de Ações Socioeducativas da Capital. Na situação, houve a necessidade da intervenção do Poder Judiciário no sentido de determinar que o Estado cumprisse diversas medidas a fim de garantir o referido direito aos jovens e adolescentes internados (ESTADO..., 2019).

A decisão judicial estabeleceu a obrigação de o Estado do Rio de Janeiro criar e colocar em funcionamento nas unidades de internação o Grupo de Apoio à Educação, que se encontra previsto 
no artigo 66 do Regimento do Departamento Geral de Ações Socioeducativas, além de implantar o terceiro turno escolar, sob pena de multa diária no valor de 100 (cem) mil reais (ESTADO..., 2019).

Em adição, afirmou que o Estado deveria garantir a prestação ininterrupta dos serviços educacionais nas unidades de internação, inclusive no período de férias escolares das unidades "extramuros", também sob pena de multa, sendo esta única e estabelecida em 200 (duzentos) mil reais por unidade e pelo período de férias no qual o serviço fosse interrompido. Por fim, foi fixado o prazo de 180 (cento e oitenta) dias para que fossem criadas salas de aulas com estrutura física e de pessoas, tendo multa mensal de 100 (cem) mil reais caso ocorresse seu descumprimento (ESTADO..., 2019).

Percebe-se, assim, que há uma certa distância entre a realidade brasileira e o que prevê a Constituição Federal de 1988, o ECA e o SINASE. Ainda resta muito a se fazer, principalmente em relação às políticas públicas e sociais básicas de atendimento educacional aos jovens e adolescentes em cumprimento de medida socioeducativa de internação, para que seus direitos sejam garantidos em uma perspectiva de cidadania e seu processo de (re)socialização seja eficaz.

\section{Conclusão}

As crianças e os adolescentes são titulares do direito fundamental à educação, previsto na Convenção da Organização das Nações Unidas Sobre os Direitos da Criança, na Constituição Federal de 1988, na Lei no 8.069/90 (Estatuto da Criança e do Adolescente), nas Regras das Nações Unidas para Jovens Privados de Liberdade de 1990, na Lei no 12.594/12, dentre outros materiais normativos.

Neste aspecto, vislumbra-se que o objetivo de todas essas cargas normativas consiste na elucidação e na preservação dos direitos das crianças e dos adolescentes. Dentre estes, se estabeleceu que seja observada a natureza pedagógica, de reeducação e de ressocialização na aplicação das medidas socioeducativas ao adolescente em conflito com a lei, despertando os valores sociais essenciais para sua formação.

Da mesma forma, tais legislações albergam a educação, reconhecendo-a como direito público e subjetivo. No presente contexto, entretanto, as políticas sociais não têm se mostrado eficazes garantidoras à educação, posto que seus olhares não alcançam a (re)socialização de muitos adolescentes e jovens que se encontram cumprindo a medida socioeducativa (MSE) de internação.

A essência da ressignificação não traduz com fidelidade o propósito da MSE, pois não faz com que o jovem ou o adolescente em situação de conflito com a lei rompa com as premissas da violência e o deslocamento social vivenciados, tampouco lhe converge ao efetivo direito fundamental de acesso à educação.

Compreendemos que a medida socioeducativa de internação, a qual priva a liberdade do adolescente, deve ter como escopo não somente restrições de direitos, como o de ir e vir, mas também o fundamento em abraçar os jovens para o estudo, de modo que estes venham atender com eficiência e integralidade o processo de alcance à cidadania através da educação.

A educação ofertada dentro das unidades de internação se faz essencial para auxiliar o processo de ressignificação na vida dos jovens e adolescentes em situação de conflito com a lei. Além disso, ainda pode propiciar formação profissional, lazer e, sobretudo, a inclusão emancipatória do jovem excluído, permitindo, então, que haja o deslocamento infracional violento para o diálogo e acolhimento social.

A medida socioeducativa de internação demonstrará eficácia ao deixar de se limitar ao seu caráter eminentemente punitivo, que busca somente responsabilizar o jovem ou o adolescente pelas consequências lesivas do ato infracional, e passar a ser verdadeiramente educativa, visando processos internos e externos de aprendizagem. 
Verifica-se que há uma imperiosa necessidade de se fomentar a discussão sobre o direito à educação e seu fornecimento nos espaços de privação de liberdade, expandindo-a principalmente entre aqueles que aplicam a lei e acompanham a execução das medidas socioeducativas para os adolescentes e os jovens de até 21 (vinte e um) anos de idade.

Concluímos, por fim, que a educação contribui para a efetivação do direito fundamental à proteção integral dos jovens e adolescentes em conflito com a lei, uma vez que seu mecanismo de inclusão social amplia os horizontes do indivíduo, ao passo que oferta condições para que ele consiga acreditar na existência de um futuro melhor, em que a dignidade faz morada e se suspende o ciclo da reiteração infracional, o qual até então vem subsistindo.

\section{Referências}

ABRAMO, Helena Wendel; LEÓN, Oscar Dávila. Juventude e adolescência: referências conceituais. São Paulo: Ação Educativa, 2005. Disponível em: https://bibliotecadigital.mdh.gov.br/jspui/bitstream/192/212/1/LEON_ABRAMO_ juventudeeadolescencianobrasil_2005.pdf. Acesso em: 23 dez. 2020.

ALVES, Franciele Caroline. Eficácia das medidas socioeducativas segundo a doutrina brasileira. Trabalho de Conclusão de Curso (Bacharelado em Direito) - Universidade do Vale do Itajaí, Itajaí, 2006.

ANTÃO, Renata Cristina do Nascimento. O direito à educação do adolescente em situação de privação de liberdade. Orientador: Nina Beatriz Stocco Ranieri. 2012. 228 f. Dissertação (Mestrado em Direito) - Programa de Pós-graduação Strictu Sensu da Faculdade de Direito da Universidade de São Paulo, Universidade de São Paulo, São Paulo, 2012. BAZON, Marina Rezende; SILVA, Jorge Luiz da; FERRARI, Renata Martins. Trajetórias escolares de adolescentes em conflito com a lei. Educação em Revista, Belo Horizonte, v. 29, n. 2, p. 175-199, jun. 2013. Disponível em: https://www. scielo.br/pdf/edur/v29n2/08.pdf. Acesso em: 5 dez. 2020.

BRASIL. [Constituição (1988)]. Constituição da República Federativa do Brasil de 1988. Brasília, DF: Presidência da República, [2020]. Disponível em: http://www.planalto.gov.br/ccivil_03/constituicao/constituicao.htm. Acesso em: 25 nov. 2020.

BRASIL. Lei no 8.069, de 13 de julho de 1990. Dispõe sobre o Estatuto da Criança e do Adolescente e dá outras providências. Brasília, DF: Presidência da República, [2020]. Disponível em: http://www.planalto.gov.br/ccivil_03/leis/ 18069.htm. Acesso em: 24 nov. 2020.

BRASIL. Lei no 9.394, de 20 de dezembro de 1996. Estabelece as diretrizes e bases da educação nacional. Brasília, DF: Presidência da República, [2020]. Disponível em: http://www.planalto.gov.br/ccivil_03/leis/19394.htm. Acesso em: 19 ago. 2020.

BRASIL. Lei $n^{\circ} 12.594$, de 18 de janeiro de 2012. Institui o Sistema Nacional de Atendimento Socioeducativo (Sinase), regulamenta a execução das medidas socioeducativas destinadas a adolescente que pratique ato infracional; e altera as Leis [...]. Brasília, DF: Presidência da República, [2020]. Disponível em: http://www.planalto.gov.br/ccivil_03/_Ato20112014/2012/Lei/L12594.htm. Acesso em: 17 ago. 2020.

BRASIL. Procuradoria Geral da República. STJ: medida socioeducativa pode ser cumprida até 21 anos de idade. Ministério Público Federal, Procuradoria-Geral da República, Brasília, DF, 25 jun. 2018. Disponível em: http://www.mpf. $\mathrm{mp}$.br/pgr/noticias-pgr/stj-medida-socioeducativa-pode-ser-cumprida-ate-21-anos-de-idade. Acesso em: 20 dez. 2020. CARREIRA, Denise; ANDRADE, Leila. A educação popular em contextos de privação de liberdade: a arte-educação na Fundação Casa. Revista e-Curriculum: revista do Programa de Pós-Graduação em Educação da PUC/SP, São Paulo, v. 14, n. 2, p. 414-436, abr./jun. 2016. Disponível em: https://revistas.pucsp.br/curriculum/article/view/27665. Acesso em: 4 dez. 2020.

CONSELHO NACIONAL DE JUSTIÇA (CNJ). Panorama nacional: a execução das medidas socioeducativas de internação. Programa Justiça ao Jovem. Brasília, DF: Conselho Nacional de Justiça, 2012.

COSTA, Cibele Soares da Silva; ALBERTO, Maria de Fatima Pereira; SILVA, Erlayne Beatriz Félix de Lima. Vivências nas Medidas Socioeducativas: possibilidades para o Projeto de Vida dos Jovens. Psicologia: Ciência e Profissão, Brasília, DF, v. 39, 2019. Disponível em: https://www.scielo.br/scielo.php?script=sci_arttext\&pid=S1414-98932019000100149\&tlng=pt. Acesso em: 25 out. 2020.

CUNHA, Eliseu de Oliveira. Educação de adolescentes privados de liberdade: especificidades da EJA no sistema socioeducativo. In: Encontro Internacional de Alfabetização e Educação de Jovens e Adultos, 2., 2015, Salvador. Anais eletrônicos [...]. Salvador: MPEJA/UNEB, 2015. Disponível em: https://alfaeejablog.files.wordpress.com/2016/03/educacao-de-adolescentes-privados-de-liberdade.pdf. Acesso em: 24 nov. 2020. 
CUNHA, Eliseu de Oliveira; DAZZANI, Maria Virgínia Machado. A escolarização de adolescentes infratores em um contexto de privação de liberdade. Revista Brasileira Adolescência e Conflitualidade, Belo Horizonte, n. 17, p. 34-43, 2018. Disponível em: https://revista.pgsskroton.com/index.php/adolescencia/article/view/5162. Acesso em: 26 nov. 2020. CUSTÓDIO, André Viana. Direito da criança e do adolescente. Criciúma: Universidade do Extremo Sul Catarinense (UNESC), 2009.

DIGIÁCOMO, Murillo José; DIGIÁCOMO, Ildeara Amorim. Estatuto da criança e do adolescente anotado e interpretado. 8. ed. Curitiba: Fundação Escola do Ministério Público do Estado do Paraná, 2020. E-book (710 p.). Disponível em: http://femparpr.org.br/site/wp-content/uploads/2017/07/eca_versao_2020.pdf. Acesso em: 29 set. 2020.

ELIAS, Roberto João. Direitos fundamentais da criança e do adolescente. São Paulo: Saraiva, 2005.

ELIZEU, Ludimyla Bretas. Aplicabilidade das medidas socioeducativas. Nova Venécia, 2010.

ESTADO terá de garantir educação a jovens internados no Degase. Tribunal de Justiça do Estado do Rio de Janeiro (TJRJ), Rio de Janeiro, 19 mar. 2019. Disponível em: http://www.tjrj.jus.br/noticias/noticia/-/visualizar-conteudo/5111210/6254027. Acesso em: 26 nov. 2020.

FOUCAULT, Michel. Vigiar e punir: nascimento da prisão. 42. ed. Tradução: Raquel Ramalhete. Petrópolis: Vozes, 2014. FRANCISCO, Marcos Vinicius; MURGO, Camélia Santina. O papel da escola na trajetória de adolescentes autores de atos infracionais: concepções de professores. Revista Nuances: estudos sobre Educação, Presidente Prudente, v. 26, n. 1, p. 98-120, jan./abr. 2015.

FREIRE, Paulo. Política e educação. 5. ed. São Paulo: Cortez, 2001.

ISHIDA, Valter Kenji. Estatuto da criança e do adolescente: doutrina e jurisprudência. 16. ed. São Paulo: Atlas, 2015.

JUNG, Valdir Florisbal. A educação como instrumento de ressocialização do jovem infrator. In: Semana de Extensão, Pesquisa e Pós-Graduação - SEPesq, 14., 2018, Porto Alegre. Anais eletrônicos [...]. Porto Alegre: Centro Universitário Ritter dos Reis, 2019. Disponível em: https://www.uniritter.edu.br/files/sepesq/arquivos-trabalhos-2019-2/10-valdir-florisbal-jung-a-educacao-como-instrumento-de-ressocializacao-do-jovem-infrator.pdf. Acesso em: 4 dez. 2020.

MATOS, Priscila Santini. Aplicabilidade e eficácia das medidas socioeducativas impostas ao adolescente infrator. Trabalho de Conclusão de Curso (Bacharelado em Direito) - Universidade Tuiuti do Paraná, Curitiba, 2011.

MEDEIROS, Clayton Gomes; RODRIGUES, Hanslilian Correia Cruz. A judicialização do direito à educação básica. Cadernos da Escola de Direito e Relações Internacionais, Curitiba, v. 1, n. 20, 2014. Disponível em: https://portaldeperiodicos.unibra-sil.com.br/index.php/cadernosdireito/article/view/3036. Acesso em: 21 set. 2020.

MORAIS, Iolanda Ferreira de. O direito humano à educação básica: o Ensino Fundamental de Pernambuco. Orientadora: Aíra Maria Monteiro Silva. 2019. 105 f. Dissertação (Mestrado em Direitos Humanos) - Programa de Pós-Graduação em Direitos Humanos, Universidade Federal de Pernambuco, Recife, 2019.

OLIVEIRA, Euzamar de Ribeiro. A política educacional direcionada a adolescente em cumprimento de medida socioeducativa no Centro de Internação para Adolescente de Anápolis (CIAA). Orientadora: Denise Carmen de Andrade Neves. 2014. 121 f. Dissertação (Mestrado em Serviço Social) - Programa de Mestrado em Serviço Social, Pontifícia Universidade Católica de Goiás, Goiânia, 2014.

PADOVANI, Andréa Sandoval; RISTUM, Marilena. A escola como caminho socioeducativo para adolescentes privados de liberdade. Revista Educação e Pesquisa, São Paulo, v. 39, n. 4, p. 969-984, out./dez. 2013. Disponível em: https:// www.scielo.br/pdf/ep/v39n4/aop1064pt.pdf. Acesso em: 5 dez. 2020.

PRATES, Flávio Cruz. Adolescente Infrator: a prestação de serviços à comunidade. Curitiba: Juruá, 2001.

ROQUETE, Liana Correia. O direito à educação no contexto de medida socioeducativa de internação. In: Congresso Ibero-Americano de Política e Administração da Educação, 4., 2014, Porto, Portugal. Anais eletrônicos [...]. Porto: Associação Nacional de Política e Administração da Educação (ANPAE), 2014. Disponível em: https://anpae.org.br/ IBERO_AMERICANO_IV/GT3/GT3_Coimunicacao/LianaCorreiaRoquete_GT3_integral.pdf. Acesso em: 24 nov. 2020.

SILVA, Karla Cristina da. A garantia do direito à educação para adolescentes e jovens em cumprimento de medida socioeducativa de internação. Orientadora: Alice Miriam Happ Botler. 2019. 206 f. Tese (Doutorado em Educação) Programa de Pós-Graduação em Educação, Universidade Federal de Pernambuco, Recife, 2019.

VOLPI, Mario (org.). O adolescente e o ato infracional. 4. ed. São Paulo: Cortez, 2002.

Data de submissão: 08/12/2020

Data de aceite: $24 / 12 / 2020$ 
